\title{
Building foundations for the future: A case study with LTA Youth
}

\author{
Sam Richardson, Matt Smith \& Merlin van de Braam \\ Lawn Tennis Association, Great Britain.
}

\begin{abstract}
This article discusses modern challenges experienced when developing tennis players including low levels of physical literacy. It then outlines the needs of a young child and learning strategies that can be used. A brief overview of some practical strategies for engaging early years participants, using a player-centred approach, are shared using examples from LTA Youth with explanations of how each exercise integrates key principles to attract and retain early years participants.
\end{abstract}

Key words: learning strategy, early years, attraction, player-centred.

Received: 10 November 2021

Accepted: 1 December 2021

Corresponding author:

Merlin van de Braam. Email: merlin.van-de-braam@lta.org.uk

\section{A CHALLENGING SPORT AND PHYSICAL ACTIVITY CONTEXT}

Physical activity has been linked to better psychological well-being and improved physical health among children and adolescents, but studies have shown that sedentary time increases for all children between ages 6-11yrs (Jago et al.,2019). A project in children's physical literacy in the UK revealed a $6.2 \%$ decline in measures of balance, $19.7 \%$ decline in aiming and catching, $15.8 \%$ decrease in manual dexterity and $18.1 \%$ deterioration in overall physical development (Hart, 2015).

Alongside declining physical activity, studies have shown that $79 \%$ of Generation Alpha (age 5-9yrs in 2020) engage in a wide and extensive variety of television programmes, films, videos, music, and games (Beano, 2019). These games and videos are designed to engage young audiences through colourful, stimulating, and playful gamification concepts.

The decline in children's levels of physical activity and physical literacy presents a serious challenge for tennis because our sport is a complex coordination sport that requires a higher degree of skill when compared to many alternative activities. The above challenge sets a clear direction for the future of tennis and coaching; on-court programmes need to continuously evolve to meet the demands of the future participant; a participant that brings low levels of coordination coupled with an expectation for highly stimulating and fun activities.

It is critical that tennis coaching curriculums rise to this modern-day challenge by developing innovative, engaging environments for children that develop better physical literacy in tandem with long-term technical, tactical, physical, and psychological competence for tennis.

\section{EFFECTIVE LEARNING STRATEGIES AND DELIVERY PRINCIPLES FOR EARLY YEARS}

Early years children are like sponges with a high degree of neuroplasticity that allows for coaches to literally 'wire and sculpt' brains and movement patterns (Johnston et al, 2001). This exciting stage of tennis coaching presents huge opportunity if the right strategies are employed.

\section{Player centred approach}

To compete with challenges with digital screen times and video gamification, consider using stimuli, learning aids and activities that create an enriching environment like a playground or reception classroom. A fully child-centred philosophy will see tennis adapted to fit the needs of the child, as opposed to the child having to adapt to fit the needs of the adult game of tennis.

\section{Importance \& benefits of play}

Play is crucial to the learning and development of children in the early years (Fleer, 2021). Children in these early years (4-6) are curious, like to explore, investigate and are creative. They therefore need opportunities to investigate, satisfy their curiosity, explore the environment (inside and outside of the play area) to extend their sense of wonder, experience success and develop a positive attitude towards learning. Play is therefore purposeful, and it can only truly be play when the child has chosen what to do, where and how to do it, a childdetermined approach (Smidt, 2010).

\section{Harnessing imagination, storytelling \& analogy}

The environment that we plan, set-up and create needs to allow young children to utilise their imagination through a shared ownership of the narrative, which helps them engage for longer periods. The use of effective storytelling and analogy from the coach in sessions can aid learning and mastery in early years coaching. Practically speaking, this 
may mean a tennis ball becomes a 'meteorite' for a session with early years. Hitting a ball over the net onto a rubber spot could be described as a 'frog landing on a lily-pad.' Research has shown that use of analogy learning is an effective learning and motor development strategy (Masters \& Maxwell, 2004).

\section{Know their world}

Investing time and energy getting to know the world of a child can helpengagement and learning. For example, understanding key characters from their favourite programmes, films and cartoons can stimulate interest and a sense of familiarity within tennis.

\section{Skill based (not technical/model-based) coaching}

Early years sessions need to move away from traditional model-based coaching which can undermine long term skill development (Reid et al., 2007). Instead, sessions should expose kids to a full 360 experience of their surroundings, for them to organise their bodies to their surroundings and adapt to learn implicitly. Practically speaking, the direction of the racket face and how to hold the racket (on the handle) is in most cases all the technical input an early year's child should have.

\section{ADDRESSING THE NEEDS OF THE PRE-SCHOOL CHILD}

LTA Youth is a programme created to help more children enjoy the benefits of playing and staying in tennis, whatever their age, gender, ability, disability, or background. It has been developed to be fun, inclusive, and competitive, with specially designed progressive coaching and content that will help develop children aged 4-18 years.

\section{LTA Youth: Stages}

Approximately 1.25 million children aged 4-15yrs play tennis once a month in the United Kingdom (LTA, 2021). To facilitate the attraction of more early year's participants into the game of tennis, the LTA Youth programme introduced a 'Blue' stage which precedes the red-orange-green-yellow ball framework. LTA Youth Blue stage is designed for children who are approximately 4-6 years old to develop their fundamental movement skills and have greater success at red ball tennis and beyond.

\section{LTA Youth: Principles}

1. Having fun

2. Active and engaged

3. Appropriately challenged

4. Making decisions

5. Developing skills

6. Looks and feels like tennis

\section{LTA Youth Competencies}

To ensure all-round development, LTA Youth competencies spam six integrated domains. More specific learning outcomes that support the development of these higher-level descriptors are included in each exercise.

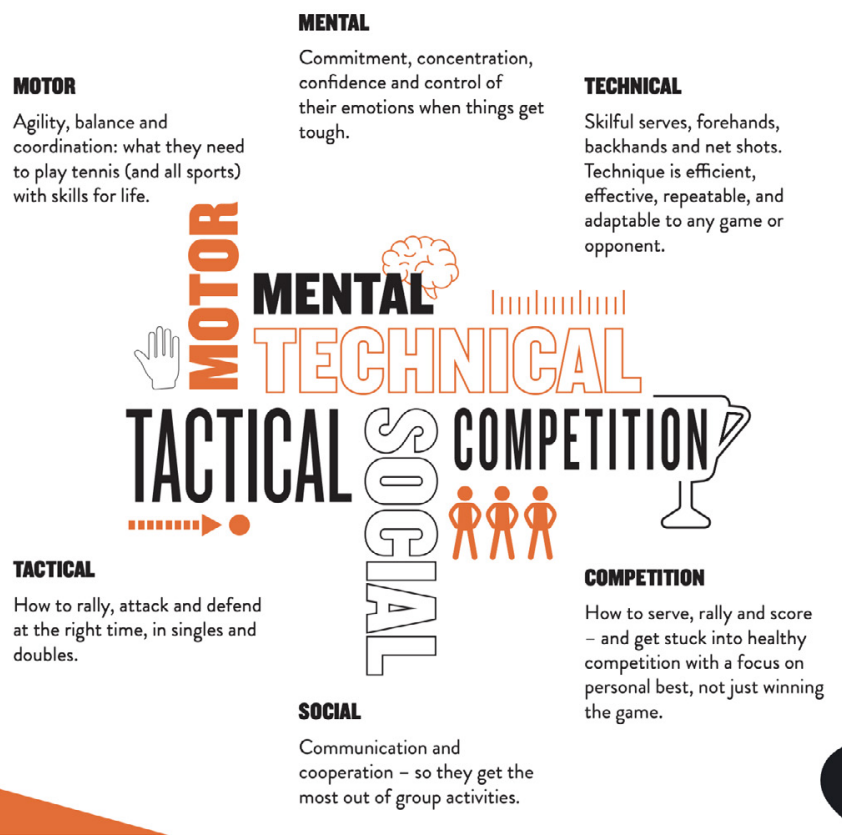

Image 1. The six integrated competency domains within LTA Youth presented as part of a parent facing resource.

PRACTICAL EXERCISES: EARLY YEARS ACTIVITIES (LTA YOUTH BLUE STAGE)

Warm up: Meet \& Greet

In this exercise, children are required to shout their name between repetitions. As a progression, the group needs to call out each player's name. Using names is a valuable social competency. Alongside this, players are required to make multi-directional movements around the purple balls on the outer perimeter and return to the middle. Coaches can describe the task using principles of imagination and analogy here to maximise engagement for early years participants. For example, instead of "run out to the blue ball and back," children can be encouraged to "take off in their spaceship and orbit a planet."

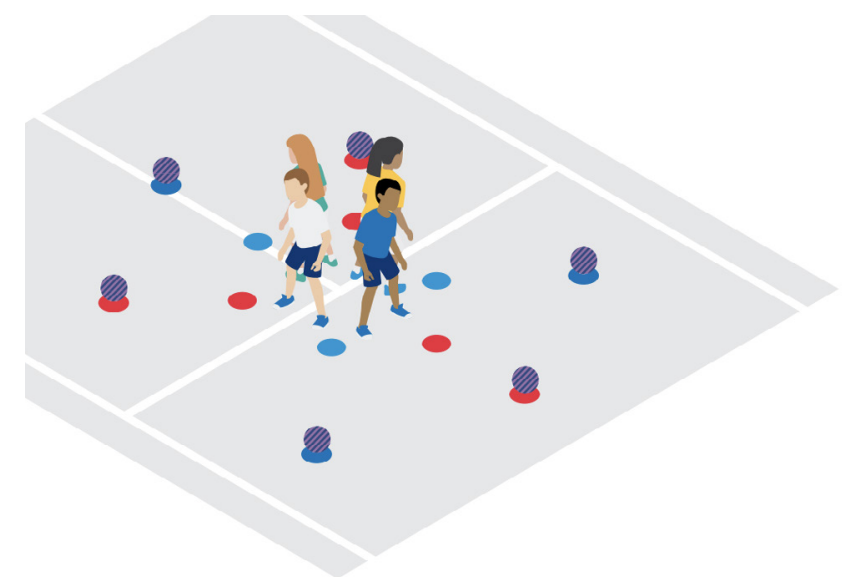

Image 2. The layout of meet and greet warm up is designed to challenge multi-directional and short movements, similar to those needed in tennis. 


\section{Body and ball: Roll and Recover}

In this exercise, children work in pairs to practice sending and receiving a larger ball along the floor. They are also developing basic reactions and how to adopt and athletic stance. Use of storytelling might see a coach describe the task as "creating a large snow man by rolling a snowball." Storytelling that is relevant to a child's world, at that time, is key to engagement.

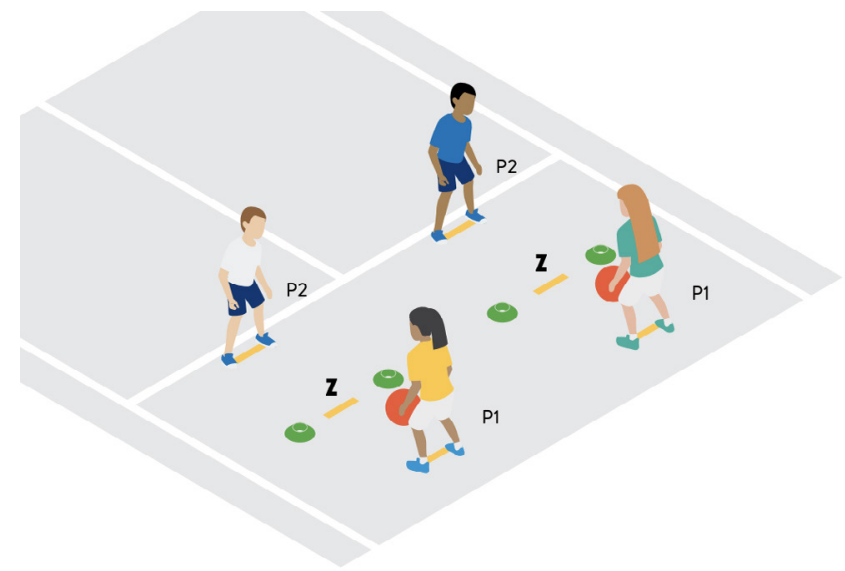

Image 3. Roll and recover exercise set up is designed to challenge send and receive skills of the early years participant.

\section{Racket \& Ball: Tennis Wizard}

In this exercise a coach uses a version of floor tennis to guide players through an exciting obstacle course, whilst teaching fundamental technical skills including 'contact point in front of shoes.' Kids will use both dominant and non-dominant hands to build skill for both forehand and backhand. If standing on the red spot, they use their right hand. If standing on the blue spot, they use their left hand. Coaches can undertake this exercise with less equipment. However, this obstacle course aligns with the principle of 'player- centred and child centred environment' using lots of stimulating obstacles and hurdles, much like a playground environment.

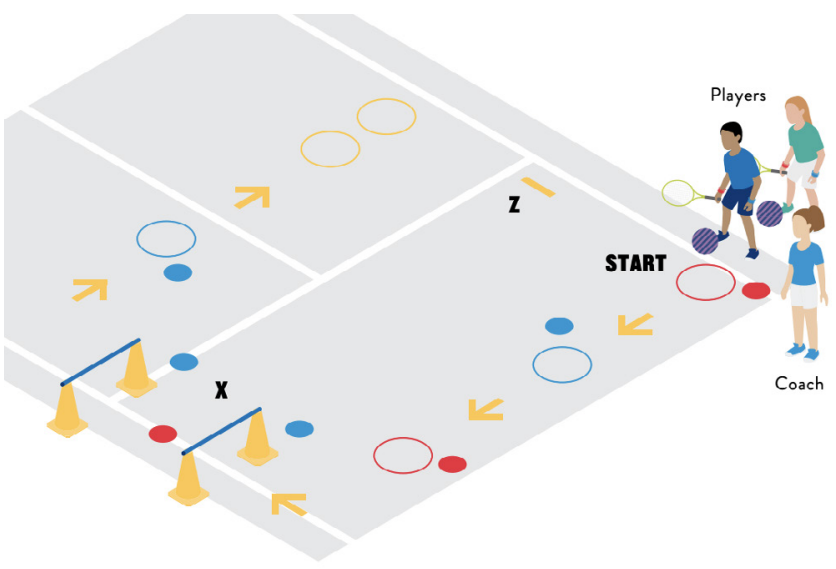

Image 4. Tennis wizard is a variation of floor tennis where extra hurdles and challenges are integrated to develop and stimulate skills.

\section{Game: Tennis Towers}

In this exercise the players start to experience the over-arm throw (serve development) whilst also building ball control for groundstrokes. Part one of the exercise involves moving the ball along the floor with a racket in hand. Coaches can harness imagination by explaining the ball is a dog and it needs to go for a walk, where the racket is the dog lead, for example. Each player can choose which set of hoops (far or near) to throw the ball from. The presence of options within the exercise builds in practice variability as well as providing decision making opportunities for children - a principle of LTA Youth. The object of the game is to knock over the yellow towers (cones). Again, coaches can harness a child's imagination by creating a fictional narrative to accompany the exercise.

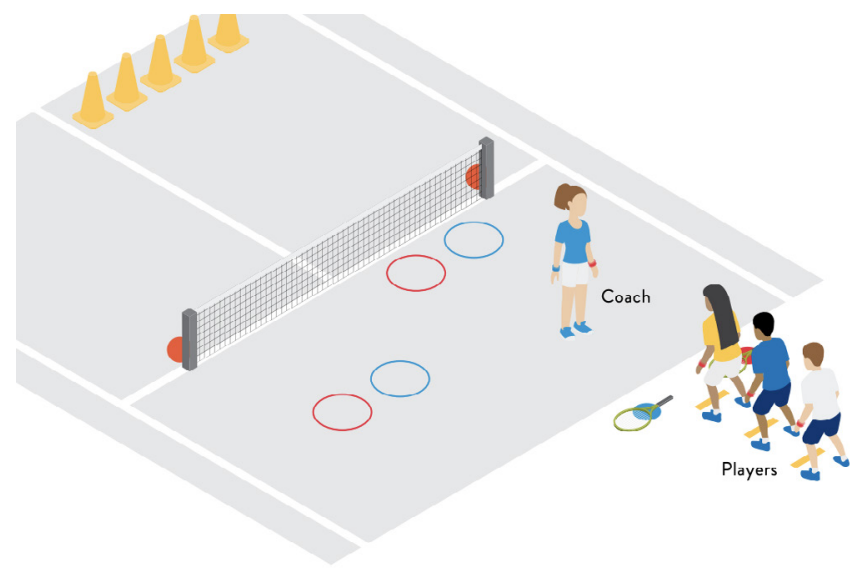

Image 5. Tennis towers is a fun exercise introducing over-arm throw whilst also testing skills already covered in the previous three parts of the lesson.

\section{CONCLUSION}

Attracting and retaining the future generation in tennis will be a significant challenge. It will require purposeful session design that is underpinned by sound learning strategies for young children. This article has highlighted a selection of recommendations through the lense of LTA Youth to help coaches with their delivery to this key audience. It is hoped that coaches utilise and apply these principles and techniques to lay foundations for future years, ages, and stages.

\section{CONFLICT OF INTEREST AND FUNDING}

The authors declare that they have no conflicts of interest and did not receive any funds to write this article.

Authors Note: LTA Youth on-court content was created collaboratively by the LTA, active British coaches and MultiSkillz experts from Coach2Competence. 


\section{REFERENCES}

Bastiaens, K. (2021). https://www.multiskillz.com/en

Beano for Brands (2019). Getting to know Gen-Alpha. Presentation delivered as part of conference proceedings at LTA National Tennis Centre.

Broadhead, P., Howard, J., \& Wood, E. (Eds.). (2010). Play and learning in the early years: From research to practice. Sage.

Fleer, M. (2021). Play in the early years. Cambridge University Press.

Harte S. (2015). Physical development and National Curriculum Levels - the incidence of neuromotor immaturity (NMI) in London primary schools and the relationship between NMI and National Curriculum measures of achievement. Paper presented at The Child Development in Education Conference. London. October 2015.
Jago, R., Salway, R., Emm-Collison, L., Sebire, S., Thompson, J., \& Lawlor, D. (2019). Association of BMI (Body Mass Index) category with change in children's physical activity between ages 6 and 11 years: a longitudinal study. International Journal of Obesity, 44, pages104-113. Retrieved December $7^{\text {th }}, 2021$, from https://www.nature.com/articles/s41366-0190459-0

Johnston, M. V., Nishimura, A., Harum, K., Pekar, J., \& Blue, M. E. (2001). Sculpting the developing brain. Advances in paediatrics, 48, 1-38.

Masters, R., Maxwell, J. (2004). Skill Acquisition in Sport. Routledge.

LTA (2021). Internal participation tracking data.

Reid, M., Crespo, M., Lay, B. \& Berry, J. (2007). Skill acquisition in tennis: Research and current practice. Journal of science and medicine in sport, 10, 1-10.

Smidt, S. (2010). Playing to learn: The role of play in the early years. Routledge.

Copyright (c) 2021 Sam Richardson, Matt Smith \& Merlin van de Braam

\section{(C) (1)}

This text is under a Creative Commons BY 4.0 license

You are free to Share - copy and redistribute the material in any medium or format - and Adapt the content - remix, transform, and build upon the material for any purpose, even commercially under the following terms:

Attribution: You must give appropriate credit, provide a link to the license, and indicate if changes were made. You may do so in any reasonable manner, but not in any way that suggests the licensor endorses you or your use.

CC BY 4.0 license terms summary. CC BY 4.0 license terms

CONTENIDO ITF ACADEMY RECOMENDADO (HAZ CLICK ABAJO)

ITF Academy 